\title{
Tecnología y seguridad jurídica en las modificaciones recientes de la ley peruana del notariado*
}

\author{
Technology and legal security in the recent \\ changes to Peruvian notary law
}

\author{
Gunther Hernán Gonzales Barrón**
}

\section{RESUMEN}

El fraude inmobiliario es uno de los más graves problemas que sufre el Perú en perjuicio de los propietarios de vivienda, en tanto las falsificaciones logran que los bienes sean traspasados a terceros de buena fe, lo que, en la práctica, hace irrecuperable el inmueble. Por tal motivo, el legislador se ha visto en la necesidad de afrontar la difícil situación mediante una reforma urgente de la ley del notariado, concretada con la aprobación del Decreto Legislativo $N^{\circ} 1232$, que entre varias reformas positivas, introduce rigurosas obligaciones del notario en orden a la identificación de personas en los instrumentos públicos y permite la emisión de traslados o copias virtuales mediante firma electrónica, con lo cual se interconecta el oficio notarial y el registro público, sin necesidad de intermediarios. No obstante, la norma también presenta serias omisiones, pues no soluciona los casos de fraude que se originan desde el arbitraje y desde el propio registro.

PALABRAS CLAVE: Fraude inmobiliario, falsificación documental, función notarial, instrumento público notarial, tecnología en identificación de personas, tecnología y seguridad jurídica.

\begin{abstract}
Real estate fraud is one of the most serious problems affecting Peru to the detriment of the homeowners, as both the counterfeits and falsifications achieved while goods are transferred to third parties acting in good faith, in practice, make the property unrecoverable.

For this reason, the legislators have seen the need to confront the difficult situation through an urgent reform of notary law, concluded with the adoption of the Legislative Decree $N^{\circ} 1232$, which among several positive reforms, introduces stringent obligations of the notary in order to verify the identification of persons in the public documents and allow the issue of transfers or virtual copies by means of electronic signature; in this way the office of notary and the public register are interconnected, without the need for intermediaries. However, the standard also presents serious omissions, and therefore does not solve the cases of fraud that originate from the arbitration and from the public record itself.

KEY WORDS: Real estate fraud, document falsification, notarial function, public notarial instrument, technology in identification of persons, technology and legal security.
\end{abstract}

\footnotetext{
* Recibido: 7 de mayo de 2015. Aprobado: 8 de junio de 2015.

** Magistrado titular del Poder Judicial del Perú. (ggonzales@pucp.pe)
} 


\section{SUMARIO}
1. El drama social del fraude inmobiliario
2. Modificaciones de la Ley del Notariado
3. Instrumento público notarial
4. Clasificación de los instrumentos públicos notariales
5. Escritura pública
6. Acta de protocolización
7. Traslados de los instrumentos protocolares
8. Conclusiones

\section{El drama social del fraude inmobiliario}

El Perú vive, desde hace más de una década, un boom inmobiliario motivado por el crecimiento económico que empuja a la clase media a adquirir inmuebles para vivienda. Esto constituye un relevante incentivo para la industria de la construcción, que muchas veces tiene el edificio completamente vendido cuando aún se encuentra en proyecto. Por esta razón, los precios de los inmuebles se han triplicado en los últimos ocho años. Así, "un informe elaborado por el Banco Central de Reserva del Perú (BCR) revela que en los últimos años el precio por metro cuadrado de las viviendas en las áreas urbanas de Lima se ha elevado alrededor de 300\%. Así, detalla que ha subido de us $\$ 521$ el metro cuadrado, en el año 2006, a us $\$ 1,828$ durante este año en promedio. Esto significa, agrega el ente emisor, un alza pronunciada anual". ${ }^{1}$

La especulación del suelo ha crecido de modo vertiginoso, en la misma escala que el aumento de su precio, originado por la necesidad de las constructoras e inmobiliarias de adquirir terrenos con el fin de iniciar nuevos proyectos de edificación. Por tanto, la altísima rentabilidad inmobiliaria es un incentivo para el despojo de terrenos por distintos medios, incluyendo la falsificación de títulos de los legitimos propietarios, lo cual en la actualidad constituye un problema social por la gran cantidad de fraudes inmobiliarios producidos en los últimos años.

Las mafias pretenden un resultado concreto: apropiarse de los bienes ajenos para luego transferirlos a buen precio, a favor de terceros, cuartos o quintos de buena fe. Para tal efecto, se utilizan una serie de modalidades ilícitas, que aprovechan las debilidades del sistema notarial, registral, fiscal y judicial,

\footnotetext{
1 "Metro cuadrado en Lima ha subido 300\%", en Diario Perú 21, Lima, 27 de mayo, 2014, p. 10.
} 
cuyas deficiencias coadyuvan a la criminalidad organizada, sin perjuicio de las normas legales que avalan el fraude.

La falsificación de documentos se ha incrementado en el Perú por el ingreso de organizaciones dedicadas a esta ilícita actividad, cuya finalidad es apropiarse de bienes inmuebles, ${ }^{2}$ para lo cual se emplean diversas modalidades delictivas. Sin embargo, siempre existe cierto nivel de negligencia de algunos operadores jurídicos, cuya función es, precisamente, autenticar contratos e impedir la inscripción de actos irregulares. El resultado es que los delitos por esta causa se encuentran en aumento incesante, pues el análisis costo-beneficio que realizan los falsarios les hace concluir que la altísima rentabilidad de estos delitos no se neutraliza por el costo de una sanción reducida, muchas veces simbólica. ${ }^{3}$

La alarma social creada por este tipo de fraude ha motivado que, en junio de 2014, el Congreso de la República conformara una especifica comisión parlamentaria destinada a investigar los alcances del fraude inmobiliario, que hasta el momento no concluye su trabajo. Esta situación pone en peligro las inversiones, nacionales y extranjeras, así como la vivienda legítimamente adquirida.

\section{Modificaciones de la Ley del Notariado}

El Decreto Legislativo 1049, de junio de 2008, aprobó la vigente ley peruana del notariado (en adelante LN), misma que, en ese momento, no advirtió el grave problema de fraude inmobiliario que ya se vivía en nuestro país y se ha acentuado en los últimos años.

Por tanto, no es de extrañar que el legislador haya visto la necesidad de enfrentar la situación mediante una ley de urgencia, por lo cual se acaba de dictar el Decreto Legislativo 1232, publicado el 26 de septiembre de 2015, que modifica de manera sustancial la ley del notariado, bajo la premisa de introducir reformas de orden tecnológico con el fin de aumentar la seguridad jurídica de los instrumentos notariales, especialmente en la identificación de personas y en la emisión de traslados o copias virtuales que impidan la presentación de títulos falsos en el registro.

${ }^{2}$ El problema viene desde antiguo, pues basta mencionar la memoria del entonces decano del Colegio de Notarios de Lima, Carlos Augusto Sotomayor Bernós, en enero de 1993, expresada al concluir su gestión de 1991-1992, en la cual menciona como uno de los mayores problemas del notariado la falsificación de sellos, firmas y documentos notariales. El texto puede verse en: Notarius, Revista del Colegio de Notarios de Lima, No. 3, Lima 1992/1993, pp. 55-56. ${ }^{3}$ El recientemente fallecido economista Gary Becker (1930-2014) ya habia realizado estudios sobre el comportamiento económico de los criminales, en el sentido que la pena prevista por la ley, multiplicada por la posibilidad de detección, constituyen elementos que se toman en cuenta para infringir la ley. En el caso peruano, los falsificadores confian en la reducida (o ínfima) posibilidad de sanción, por lo que el delito se incrementa de manera geométrica. 


\section{Instrumento público notarial}

Los instrumentos notariales son aquellos en los cuales el notario, a solicitud de parte requirente o por mandato legal, extiende o autoriza, en ejercicio de su función, dentro de los límites de su competencia y con las formalidades de ley (artículo 23 de la LN), ${ }^{4}$ un instrumento cuya característica fundamental es la dotación de fe pública. Es decir, la narración del notario sobre un hecho se impone como verdad, se le reputa cierta. Tal consecuencia sólo puede ocurrir cuando el hecho es observado y presenciado, sobre todo por actos de vista y oído. ${ }^{5}$ Una vez percibido el hecho o acto (actum), se documenta con presunción de verdad (dictum). Como dice Vallet de Goytisolo: "ante el hecho, el notario tiene como misión la autenticación, es decir, la de dar fe de lo que ve, oye o percibe con sus sentidos".

Sin embargo, la intervención del notario en un instrumento no implica que todo él se encuentre dotado de fe pública, pues ello dependerá del tipo de instrumento y de la posición que ha tenido el notario con respecto al acto que documenta (como afirma Carnelutti). Por tanto, es necesario estar prevenido de la creencia vulgar de que toda certificación notarial conlleva dotar de fe pública a la integridad del documento, de principio a fin, e incluso en su contenido intrínseco. ${ }^{6}$

Por tal razón, y haciendo un nuevo esfuerzo interpretativo, será necesario entender que la intervención del notario convierte en público exclusivamente el ámbito sobre el cual recae la fe pública, pero no todo el instrumento. Por ejemplo, la certificación de firmas que se realiza en un contrato privado no lo convierte en instrumento público (artículo $236 \mathrm{CPC}$ ), pero si es pública (goza de fe) la atestación del notario referida a que las firmas corresponden a determinadas personas.

Por lo demás, esa es la interpretación que se deduce de una adecuada lectura de nuestro ordenamiento. Así, el artículo 26 LN dice: "Son instrumentos públicos extraprotocolares las actas y demás certificaciones notariales que se

\footnotetext{
${ }^{4}$ En palabras del civilista español José Castán Tobeñas, "los efectos de la función notarial se sintetizan y resumen en la producción del instrumento público".

${ }^{5}$ Gattari, Carlos Nicolás. Manual de derecho notarial, Depalma, Buenos Aires, 2004, p. 305.

${ }^{6}$ La ley peruana tiene una visión equivoca de la intervención notarial, en tanto pareciera suponer que toda certificación del notario le atribuye al instrumento la cualidad de público (artículos 25 y 26 LN). Esta conclusión no puede admitirse según la doctrina reiteradamente expuesta aquí, y además resulta incoherente con el artículo 236 CPC, en el cual se sostiene que la mera certificación sobrepuesta en un documento privado no lo convierte en público. Las meras legitimaciones o certificaciones no tienen la consideración de instrumentos públicos, y la razón de ello es muy simple: el notario no intervino en el origen, redacción, ni contenido del documento, en tanto los únicos autores del instrumento privado son sus autores, aunque posteriormente se le sobreponga una atestación notarial. Así puede leerse en: Ibidem, p. 310.
} 
refieren a actos, hechos o circunstancias que presencie o le conste al notario por razón de su función". Nótese que esta norma no dice que el documento privado se convierta en público, sino que se reputa instrumentos públicos a las certificaciones, lo cual indica que el documento en sí mantiene su propia naturaleza jurídica.

Por otro lado, el instrumento notarial por excelencia (escritura pública) no se agota en la fe pública. También debe agregarse la labor de consejo notarial; por lo tanto, no es correcto suponer que se trata de certificar cualquier hecho, en material en bruto, sin tamiz jurídico, pues se supone que el notario es un jurista especialmente cualificado que, antes de recibir la declaración de voluntad de las partes, explora con diligencia la intención de los contratantes, los asesora y expresa el propósito en la forma más acorde con la legalidad y a los fines lícitos.

En consecuencia, el instrumento notarial expresa la doble actividad del notario, que se resume en "dar forma" (asesorar y colaborar en la correcta expresión de la voluntad) y "dar fe” (certificar exactamente el hecho acaecido).

\section{Clasificación de los instrumentos públicos notariales}

Una primera clasificación de los instrumentos, muy importante para efectos del derecho notarial, es aquella que los divide en protocolares y extraprotocolares. Los primeros son aquellos que se documentan en el protocolo del notario, esto es, en su archivo cronológico, numerado y foliado de instrumentos, los cuales son objeto de conservación y custodia por parte del notario. Para la mejor doctrina, sólo estos son instrumentos públicos. ${ }^{7}$

Los segundos, por el contrario, son aquellos redactados y de autoría de particulares (instrumentos privados), sobre los cuales se atesta una certificación notarial determinada respecto a cierto ámbito de la fe pública (legitimación de una fotocopia o de una firma). Estos últimos, por su propia naturaleza -resultado de la acción de los particulares- no se documentan en el protocolo del notario, ni este los custodia o conserva. El artículo $25 \mathrm{LN}$ señala que son instrumentos protocolares las escrituras públicas (típico instrumento protocolar) y las demás actas que el notario incorpora al protocolo y que se encuentra obligado a conservar. El artículo 26 de la misma ley agrega que son instrumentos extraprotocolares las actas y demás certificaciones que se sobreponen al documento, y que no se conservan en el protocolo.

\footnotetext{
${ }^{7}$ Chico Ortiz, José Maria y Ramirez Ramirez, Catalino. Temas de derecho notarial y calificación registral del instrumento público, Montecorvo, Madrid, 1972, pp. 42-43.
} 
Una segunda clasificación de los instrumentos notariales distingue entre escrituras públicas y actas. Para tal efecto, debe considerarse que la intervención notarial puede referirse sólo a la comprobación de un hecho de la realidad material o fenomenológica (por ejemplo: el estado de una cosa), en cuyo caso el instrumento que lo contiene es típicamente un acta que narra o relata una circunstancia que es objeto de apreciación sensorial por el notario; en cambio, si la intervención notarial implica la recepción de una declaración de voluntad, en la cual las partes consienten sobre un determinado acto jurídico y disponen de sus intereses, entonces el instrumento que lo contiene será una escritura pública, en cuyo caso deberá identificarse a las partes, verificarse que estas actúen con capacidad, libertad y conocimiento; recibir su declaración de voluntad, y, por último, comprobar su conformidad.

La ley admite esta fundamental diferencia. El artículo 51 LN define la escritura pública como todo instrumento notarial protocolar que contiene uno o más actos jurídicos. A contrario sensu, y en principio, las actas -que son mera comprobación de hechos- no se documentan a través de escrituras públicas; por ende, son instrumentos extraprotocolares. Sin embargo, esta armonía lógica no se sigue al pie de la letra, pues existen otras consideraciones que el legislador a veces toma en cuenta, privilegiando los fines prácticos.

\section{Escritura pública}

La escritura pública es el instrumento notarial por excelencia. En él se conjugan todas las ventajas de la actividad notarial. El Decreto de Ley 1232 ha introducido diversas modificaciones en aras de prevenir las suplantaciones de identidad.

\subsection{Definición y caracteres}

El artículo 51 LN señala que la escritura pública es todo documento matriz incorporado al protocolo notarial, autorizado por notario, y que contiene uno o más actos jurídicos. La sencilla definición legal reúne todas las características que normalmente se reconoce a la escritura en doctrina:

- Instrumento típicamente notarial

- Carácter protocolar

- Los otorgantes expresan una declaración de voluntad, por la cual disponen de sus propios intereses 
La escritura pública permite la coexistencia de dos planos, teóricamente separables: el plano del negocio, que pertenece al derecho sustantivo; y el plano del instrumento, que pertenece al derecho notarial. En palabras de Nuñez Lagos, la escritura presenta una recíproca interferencia entre el negocio y el instrumento. Así, pues, una cosa es el objeto y otra la representación de ese objeto. ${ }^{8}$ Por ejemplo, supongamos un lienzo que busca reproducir algún paisaje o panorama, en donde el primero es objeto representativo y el segundo es objeto representado. En tal sentido, el notario fabrica un instrumento que representa el negocio jurídico o contrato, que sirve para hacer perdurable ese hecho.

El actum comprende las situaciones, hechos, actos o contratos de la vida jurídica; mientras que el dictum es el documento representativo que puede contener la simple narración de un hecho o ser expresivo de un negocio jurídico. En el actum, el notario interviene para recibir las declaraciones de voluntad, pero con una previa labor de consejero y previsor de las consecuencias jurídicas del negocio. En lo que se refiere al dictum, el notario es el protagonista por ser el narrador del actum; es decir, en el dictum, el notario asume la autoría del documento, con las siguientes reglas: a) En la esfera de los hechos, el notario narra fielmente lo que oye y percibe por sus sentidos; b) En la esfera negocial o contractual, el notario recoge con autenticidad las declaraciones de voluntad de los otorgantes.

\subsection{Sujetos del instrumento}

La ley no define los sujetos de la escritura pública; sin embargo, hace una distinción que no puede obviarse. En efecto, el artículo 54-c LN establece que la introducción expresará el nombre del compareciente y sus datos personales; en cambio, los incisos $f$ y $g$ de ese mismo artículo se refieren a la intervención de un intérprete o de otra persona para los casos en que el compareciente no pueda firmar. Esta distinción permite inferir que el término compareciente denomina a las personas que formulan las declaraciones de voluntad en la escritura pública, con fines de vincularse jurídicamente. En cambio, las personas que no declaran ni estipulan, pero intervienen con miras de auxilio o apoyo, son llamados "intérprete", "otra persona" o "intervinientes", y normalmente emiten "declaraciones de ciencia", pues comprueban un hecho o prestan asistencia técnica para la configuración del instrumento (testigos a ruego, testigos de identidad, traductores, peritos, etcétera). ${ }^{9}$

\footnotetext{
${ }^{8}$ Vallet de Goytisolo, Juan. "La función notarial", en Revista de Derecho Notarial, Madrid 1984, pp. 313.

${ }^{9}$ Gattarl, Carlos Nicolás. Manual de derecho notarial, op. cit., p. 96.
} 
Desde el ámbito instrumental, las personas que declaran su voluntad ante el notario son "comparecientes", sea en nombre propio, sea como apoderados. Desde el ámbito sustantivo, por el contrario, la "parte" es el elemento personal del acto o contrato, es decir, el sujeto que dispone y reglamenta los intereses contenidos en el acto o negocio. Ambas cualidades (compareciente y parte) pueden coincidir, como ocurre cuando el vendedor actúa en nombre propio; por tanto es el que comparece directamente ante el notario como parte sustancial del contrato.

Por el contrario, ambas cualidades se separan en el fenómeno de la representación, pues el compareciente es el apoderado, mientras la parte es el poderdante. En consecuencia, la escritura, en su doble calidad de negocio documentado, también se ve influida por esta dual perspectiva, tanto desde el punto de vista instrumental como desde el civil. Por tal motivo, el otorgante directo de la escritura es el "compareciente", mientras que la persona sobre la que recaen los efectos jurídicos del negocio es la "parte".

El notario extiende la escritura, no sólo desde el punto de vista instrumental, sino, también, desde el sustantivo, pues deberá verificar que el compareciente en la escritura tenga la autorización o los poderes necesarios para obligar a la parte; en caso contrario, el negocio nacería mal formado.

El notario no es sujeto del instrumento, pues no participa en el acto, pero es el autor del instrumento, en cuanto la narración de los hechos le pertenece a él y se encuentra cubierto por la fe pública. ${ }^{10}$

\subsection{Identificación de los comparecientes}

El notario identifica a los comparecientes mediante dos mecanismos reconocidos por la ley: la fe de identidad y la fe de conocimiento (artículo 55, 1 párrafo, LN, modificado por Decreto de Ley 1232). Por el primero, el notario puede identificar a un sujeto mediante la verificación del documento nacional (DNI). Se trata de una certificación por obra de cédula oficial y auténtica. Por el segundo, el notario declara que conoce al sujeto por trato o fama, y, en tal condición, no requiere del documento nacional (así, en forma correcta, lo establece el reglamento de la ley).

\footnotetext{
10 "La autoría de la redacción que asume el notario, incluye: ante todo, la narración de los hechos que, ante él, ocurren y que percibe visu et auditu sui sensibus, tales como: que comparecen ciertas personas a quienes identifica, y que asumen las declaraciones (de voluntad, normalmente, pero que también pueden serlo sólo de verdad en caso de ser meramente confesorias), con la adición de una afirmación del notario, esencial en todos los documentos notariales, expresiva de que el documento público nace a la vida jurídica como instrumento público, y consistente en la aseveración plasmada en la frase sacramental 'doy fe', de que la narración a que se refieren sus declaraciones es exacta y veraz". Vallet de Gortisolo, Juan. "Documentos privados, legitimación de firmas y documentos públicos", en La función notarial de tipo latino, Gaceta Notarial, Lima, 2012, p. 88.
} 
La fe de conocimiento estuvo generalizada con la Ley 1511, vigente durante ochenta años, desde 1911 a 1992, cuando entró en vigor el Decreto Ley 26002. En ese momento, ya resultaba impensable que un notario conociera a los varios millones de habitantes de la capital. No obstante, es importante que se mantenga la fe de conocimiento para salvaguardar ciertos casos de notoriedad o trato con el compareciente, lo cual hace innecesario portar el documento formal. De esa manera se logra resguardar los derechos constitucionales de las personas, en cuanto se permite acceder al notario aun a las personas indocumentadas, que por eso no dejan de tener derechos humanos, siempre que el notario, de alguna u otra forma, pueda emitir fe de conocimiento o, en todo caso, auxiliarse con los testigos de identidad.

La correcta identificación de los comparecientes evita la suplantación. Lo contrario implicaría, desde una perspectiva individual, que el acto sea inútil para producir efectos entre las partes $;{ }^{11}$ pero, desde una perspectiva social, traería como consecuencia el desprestigio del sistema jurídico por falta de seguridad jurídica. Por tal motivo, se justifica ampliamente que la ley imponga al notario el deber de verificar la identidad de los otorgantes. La identificación personal se atribuye legalmente como deber del notario al momento de extender la escritura, lo cual debe realizar en forma personal y con la máxima diligencia.

La fe notarial genera una presunción de verdad que se impone de manera enérgica, en tanto el hecho se supone cierto. Por tanto, quien pretenda negar la presunción deberá anular el acto mediante la querella nullitatis, es decir, un proceso autónomo, especialmente dirigido a desvirtuar la verdad manifestada por el notario, razón por la cual debe emplazársele en juicio. ${ }^{12}$ Este efecto necesita presupuestos de justificación, como la existencia de funcionario cualificado, sometido a responsabilidad, sujeto a estrictas obligaciones de forma, y, especialmente, presenciar directamente el hecho, bajo consecuencia de incurrir en delito contra la fe pública.

\footnotetext{
11 "El instrumento público no puede cumplir sus fines sin que se acredite su legitima procedencia de la persona a quien se atribuye, la intervención real en el mismo de la persona que en él figura como interviniente, o dicho de otro modo: que no ha habido suplantación de personalidad en la creación del instrumento. Pero el tráfico jurídico exige que no haya que acreditar a posteriori, una y otra vez, que no hubo suplantación sino que pueda establecerse para siempre la presunción de aquella legítima procedencia. Y esa presunción sólo cabe si en el momento del otorgamiento el Notario se cerciora, llega al convencimiento por su ciencia propia (identificación inmediata), por la afirmación de otras personas o por los documentos que presente el compareciente (identificación mediata u objetiva) de que éste es la persona que dice ser." Avila Alvarez, Pedro. Derecho Notarial, Bosch, Barcelona, 1990, pp. 52-53.

${ }^{12}$ La querella nullitatis está imperfectamente prevista en el artículo 124 de la Ley del Notariado. Sobre el tema se dice que: "la técnica jurídica en cuanto al modo de impugnación que, a mi juicio, simboliza una mayor protección del valor probatorio legal, es la vigente en Derecho italiano, que impone instar una declaración específica de la falsedad del documento para eliminar su valor probatorio legal, declaración que puede obtenerse en un proceso civil autónomo o en un debate incidental específico inserto en el proceso civil en el que se aportó el documento". Ortells Ramos, Manuel. "Objeto, eficacia jurídica e impugnación del documento notarial (reflexiones sobre el art. 17 bis, apartado 2, de la Ley del Notariado", en Revista Crítica de Derecho Inmobiliario, No. 684, Madrid, julio-agosto, 2004, p. 1937.
} 
El presupuesto de la fe notarial se encuentra en que el sujeto con potestad fedataria ha conocido directamente de los hechos por haberlos visto, oído y percibido con sus sentidos. En este caso, hay una especie de intermediación por cuanto el notario debe identificar al compareciente a través del documento de identidad; sin embargo, la doctrina, en forma abrumadora, considera que en este ámbito también juega la fe pública, pues al notario no le basta atestar que concurrió "una persona ante él”, en cuyo caso el tráfico contractual no obtendría seguridad alguna, sino que "concurrió una persona cuya identidad es X".

Por tanto, como la escritura pública documenta un acto o negocio jurídico, entonces es necesario tener certeza de los otorgantes e intervinientes, con el fin de evitar que el negocio nazca defectuoso por falta de consentimiento de aquellos que hablan y declaran a través de la escritura. ${ }^{13}$ En tal sentido, el Decreto Ley 1232, al modificar el artículo $55 \mathrm{LN}$, ha introducido diversas exigencias sobre la identificación de los comparecientes, como medida para prevenir el fraude inmobiliario. Por lo tanto, se generaliza el indicado deber en todas las escrituras mediante una norma con rango de ley, por lo que el DS 006-2013-JUS debe entenderse derogado por una disposición que regula en forma íntegra su contenido (artículo 1 TP-CC). ${ }^{14}$

El nuevo artículo 55 LN, con la modificatoria del Decreto Ley 1232, establece las siguientes reglas concretas para lograr la adecuada identificación de las personas en sede notarial:

\footnotetext{
13 "El instrumento público no puede cumplir sus fines sin que se acredite su legítima procedencia de la persona a quien se atribuye, la intervención real en el mismo de la persona que en él figura como interviniente, o dicho de otro modo: que no ha habido suplantación de personalidad en la creación del instrumento. Pero el tráfico jurídico exige que no haya que acreditar a posteriori, una y otra vez, que no hubo suplantación sino que pueda establecerse para siempre la presunción de aquella legítima procedencia. Y esa presunción sólo cabe si en el momento del otorgamiento el Notario se cerciora, llega al convencimiento por su ciencia propia (identificación inmediata), por la afirmación de otras personas o por los documentos que presente el compareciente (identificación mediata u objetiva) de que éste es la persona que dice ser". Avila Alvarez, Pedro. Derecho Notarial, op. cit., pp. 52-53.

${ }^{14}$ Sin embargo, los cuatro primeros artículos del os deben reputarse vigentes, pues se refieren a materia distinta del control de identidad, como es el caso del límite de uso de efectivo que pueden hacer los particulares en la contratación ante notario, cuyo origen se encuentra en el lamentable crimen de una persona, y que se produjo en el interior del oficio notarial. Éste portaba una importante cantidad de dinero en efectivo. Para prevenir tal situación, se dictó la norma, que algunos consideran atentatoria de la libertad de contratación, especificamente la siguiente:

Artículo 2, primer párrafo, DS 006-2013-JUS: "Las transacciones, pago de contratos u otras obligaciones que se celebren al interior de los oficios notariales, asi como cualquier otro tipo de servicio que tengan que pagar los usuarios en dichas sedes, por montos superiores a los S/. 3,500.00 (Tres Mil Quinientos Nuevos Soles) o su equivalente en moneda extranjera, deben ser realizados necesariamente a través de empresas del sistema financiero, utilizando cualquiera de los medios de pago establecidos en el artículo $5^{\circ}$ del texto único ordenado de la Ley para la Lucha contra la Evasión y para la Formalización de la Economía, aprobado mediante Decreto Supremo № 150-2007-EF".
} 
- Cuando el distrito donde se ubica el notario tenga acceso a internet, entonces el notario exigirá el documento de identidad de los otorgantes o intervinientes, pero también efectuará la comparación biométrica de las huellas dactilares mediante el servicio brindado por el Reniec.

- Cuando no se tenga acceso a internet, por causa extraña al notario, este exigirá el documento de identidad y la consulta en línea para la verificación de datos e imágenes con el Reniec, para lo cual podrá requerir la colaboración de su Colegio. Adicionalmente, el notario podrá recurrir a otros documentos o a los testigos de identidad.

- En caso de extranjeros, residentes en el país o no, podrá exigir carnet de extranjería o pasaporte. Además accederá a la base de datos del registro de la Superintendencia Nacional de Migraciones. Pero tal posibilidad aún no está implementada; ${ }^{15}$ por tanto, el notario deberá requerir otros documentos o la intervención de testigos de identidad.

- Excepcionalmente, y por razones justificadas (ejemplo: pérdida de documentos, huellas dactilares ilegibles, etcétera), ${ }^{16}$ el notario podrá dar fe de conocimiento ${ }^{17}$ o de identidad, sin necesidad del control biométrico o de la revisión de datos en Reniec. En estos casos, cuando no haya concordancia con la realidad, el notario es automáticamente responsable cuando exista suplantación de identidad.

Por su parte, la versión original de artículo 55 in fine LN señalaba despreocupadamente que el notario no incurría en responsabilidad cuando erróneamente diese fe de identidad inducido por la actuación maliciosa de los comparecientes. La exoneración de responsabilidad era demasiado general, por lo que alentaba la impunidad del notariado; en tanto, los perjudicados no recibían siquiera una indemnización.

\footnotetext{
1510 DCTF-LN, incorporada por el Decreto Ley 1232: "Para la identificación de los extranjeros residentes o no en el pais a que se refiere el artículo 55 de la presente ley, la Superintendencia Nacional de Migraciones deberá poner a disposición de los notarios el acceso a la información de la base de datos del registro de carnés de extranjería, pasaportes y control migratorio de ingreso de extranjeros, en el plazo de ciento ochenta (180) días calendario, contados desde la vigencia del presente Decreto Legislativo". Es decir, a fines de marzo de 2016, en teoría, el sistema debería estar operativo.

${ }^{16}$ La obligación de verificación biométrica quedaba exceptuada, para fines particulares, cuando la identidad del compareciente ya había sido comprobada en anteriores instrumentos notariales extendidos ante el mismo notario (artículo 7-10 Decreto Supremo 006-2013-JUS). No obstante, si bien esta norma debe entenderse derogada por la nueva regulación del Decreto Ley 1232, tal caso calza perfectamente entre aquellas "razones justificadas" que exoneran del deber de comparación biométrica.

${ }^{17}$ La fe de conocimiento requiere "el conocimiento directo y personal por el notario de los otorgantes, consistente en la convicción racional de que el otorgante es la persona que por sus nombres y apellidos se expresa en el instrumento". Jaurrieta Alegria, Ana Isabel. "Identificación de los comparecientes", en Gómez-Ferrer Sapiña, Rafael (Coord.), Jornadas de estudio sobre el nuevo reglamento notarial, Thomson-Civitas, Cizur Menor, 2008, p. 35.
} 
Sin embargo, la nueva redacción del artículo 55 LN, modificado por Decreto Ley 1232, cambia la situación anterior, en cuanto establece que el notario sólo quedará liberado de responsabilidad cuando en forma estricta cumpla los deberes legales de identificación en las diferentes hipótesis (peruanos o extranjeros, sea que se trate de oficios notariales en lugares con acceso a internet, o cuando no haya ese acceso, lo que podría exigir la presentación de otros documentos ${ }^{18} \mathrm{o}$ de testigos de identidad), y además cuando haya actuación maliciosa de los comparecientes o de otras personas. Por tanto, si el notario ejecuta los deberes de control biométrico y de comprobación de datos en línea, entonces difícilmente podría haber problemas de identidad, máxime cuando también se le impone obligaciones de diligencia para atajar la malicia del tercero.

La conclusión es que la perspectiva ha quedado modificada, pese a mantenerse buena parte del texto primigenio: el notario, hoy, es responsable por las suplantaciones, salvo que hubiese cumplido los estrictos deberes legales con plena diligencia. En cambio, cuando el notario inobserva alguna de las reglas de su profesión respecto a la identificación de los sujetos (lex artis), entonces el daño se produce por culpa de él, al margen que el tercero también ha contribuido al resultado, por lo que es responsable civil.

\subsection{Estructura del instrumento}

La técnica documental tiene como principal contenido el estudio de la estructura interna de los documentos, lo cual significa la distribución y combinación de las distintas partes que integran su composición o texto. El manejo fluido de la estructura interna pone de manifiesto la habilidad para combinar los distintos elementos que plantea cada documento en su individualidad. Esta división en secciones o partes posibilita estudiar en forma separada cada una de ellas, con lo cual se logra mayor precisión y detalle en el análisis, ${ }^{19}$ así como la fácil lectura para los interesados.

En doctrina, se sugiere que la estructura de la escritura pública se divida en dos partes sustanciales: el texto negocial y las constancias notariales. En efecto, una cosa es la voluntad de las partes y otra muy distinta las menciones del notario (afirmaciones de verdad, juicios o menciones). Es de suma importancia

\footnotetext{
${ }^{18}$ Un documento de identidad supletorio, adicional al DNI, es aquel "documento oficial expedido por autoridad competente de su pais de origen que sirva a efectos de identificación [...] en todo caso, el documento utilizado deberá contener fotografía y firma del otorgante". Ibidem, p. 37.

${ }^{19}$ Etchegaray, Natalo Pedro. Técnica y práctica documental. Escrituras y actas notariales, Astrea, Buenos Aires, 2003, pp. 69-70.
} 
establecer el sujeto de quien emana una determinada aseveración, pues así se tendrá en claro al responsable de ello. Por ejemplo, la declaración de titularidad de un inmueble o la ausencia de cargas al dominio son siempre manifestaciones del transmitente, y nunca del notario; por lo tanto, este último no tiene responsabilidad por la veracidad o no de esa afirmación. ${ }^{20}$

Por otra parte, Etchegaray ${ }^{21}$ propone la siguiente estructura interna:

- Comparecencia: donde se expresa lugar, fecha, nombre del notario, personas que comparecen, datos personales; el juicio de capacidad notarial y la fe de conocimiento o identidad.

- Intervención: el notario deja constancia de que los comparecientes actúan por sí (en nombre propio) o en representación de otros.

- Exposición-estipulación: las partes exponen el negocio, mediante cláusulas numeradas que deben ir de lo esencial a lo accesorio.

- Constancias notariales: se incluyen las constancias de tipo fiscal y administrativo que las leyes impongan. El instrumento cierra con la mención de que ha sido leído, y el consiguiente otorgamiento y firma de las partes ante el notario.

La ley peruana establece que la estructura interna de la escritura pública se divida en tres partes: introducción, cuerpo y conclusión (artículo 52 LN).

La introducción permite expresar la comparecencia de los otorgantes y sus datos personales y de identificación; en el cuerpo se contiene la declaración de voluntad de las partes y los comprobantes de representación u otros que sean necesarios; por último, la conclusión contiene la mención de que el instrumento ha sido leído, la ratificación del consentimiento por los otorgantes, y la firma consiguiente.

La introducción expresará lo siguiente, según el artículo 54 LN:

- Lugar y fecha del instrumento

- Nombre del notario

- Comparecencia de los sujetos, con sus respectivos datos de identificación y personales; así como la constancia de actuar en nombre propio o en representación, con indicación del documento que lo autoriza

- Intervención de intérprete cuando uno de los comparecientes ignore el idioma en que se redacta el instrumento

\footnotetext{
${ }^{20}$ Ibidem.

${ }^{21}$ Ibidem, pp. 70-71.
} 
- Intervención de una persona (testigo a ruego), en el caso que el compareciente sea iletrado, no sepa o no pueda firmar, sea ciego o tenga otro defecto que haga dudosa su habilidad, sin perjuicio de que el compareciente imprima su huella digital

- Juicio del notario sobre capacidad, libertad y conocimiento con el que actúan los comparecientes

- Fe de conocimiento o de identificación

- La mención de que la declaración de voluntad se materializa con minuta, o sin ella

La redacción del artículo $54 \mathrm{LN}$ no ha sido formalmente modificada. Sin embargo, el Decreto Ley 1232 introduce un nuevo párrafo (final) en el artículo $55 \mathrm{LN}$, por el cual se establece que el notario deberá dejar constancia en el mismo instrumento de las distintas verificaciones o constataciones a las cuales está obligado, o, en caso contrario, la justificación por no haber seguido el procedimiento impuesto. Por tanto, el notario tendrá que dejar alguna de las siguientes menciones en la introducción de la escritura:

- "El notario verificó la identidad de los comparecientes mediante la presentación de su documento nacional de identidad y la comprobación de huellas dactilares por control biométrico del Reniec, cuyo resultado se inserta escaneado en el instrumento"

- "El notario verificó la identidad de los comparecientes mediante la presentación de su documento nacional de identidad y la comprobación con la base de datos del Reniec, cuyo resultado se inserta escaneado en el instrumento, y que es consistente con los datos físicos de la persona que se presentó ante mi oficio"

- "El notario verificó la identidad de los comparecientes mediante la presentación de su carné de extranjería (o pasaporte), y la comprobación con la base de datos de la Superintendencia de Migraciones, cuyo resultado se inserta escaneado en el instrumento, y que es consistente con los datos físicos de la persona que se presentó ante mi oficio"

- "El notario verificó la identidad de los comparecientes mediante la presentación de su carné de extranjería (o pasaporte), y con la presentación de otros documentos consistentes con su identidad (licencia de conducir o carné universitario, por ejemplo) o la declaración de testigos (indicación de nombres) que comprueban la identidad de los otorgantes del acto jurídico, ante la ausencia de información de la Superintendencia de Migraciones" 
- "El notario da fe de conocimiento del otorgante del acto jurídico, pues declara conocerlo por trato en los últimos años; en consecuencia, es superflua cualquier otra comprobación, bajo responsabilidad"

- "El notario da fe de identidad del otorgante del acto jurídico, pues en anteriores escrituras públicas (fechas) se comprobó tal hecho con el control biométrico de huellas dactilares, por lo que es superfluo cualquier otra constatación, bajo responsabilidad"

El cuerpo contiene fundamentalmente la declaración de voluntad de las partes expresada en minuta previa, o sin ella cuando la ley lo permita. Ello fija el conjunto de derechos y obligaciones asumidas por las partes. Además, se insertará el comprobante que acredita la representación, si fuera el caso, o se cualquier otro documento exigible o conveniente para conformar o completar la citada declaración de voluntad (artículo 57 LN).

El cuerpo de la escritura se corresponde con el texto del negocio, por lo que sus autores directos son las mismas partes, ${ }^{22}$ sin perjuicio de que el notario pueda ejercer el deber de consejo, con la finalidad de apoyar a los interesados en la adecuación del negocio a la legalidad. Pero en cualquier caso esa participación es propia a la de un asesor cualificado, ${ }^{23}$ pero no lo convierte en declarante o creador de la declaración.

El contenido del cuerpo, expresado en los derechos y obligaciones de las partes, servirá para que el notario pueda calificar el acto o negocio, con el fin de titular la escritura pública, ${ }^{24}$ pero con la salvedad de que el nomen iuris es señalado normalmente por los interesados. Sin embargo, el notario puede rectificarlo cuando exista error patente.

\footnotetext{
22 Etchegaray, Natalo Pedro y Capurro, Vanina Lella. Derecho notarial aplicado, Astrea, Buenos Aires, 2011, p. 285.

23 "El notario debe velar por el cumplimiento de la legalidad vigente. La moderna doctrina notarialista ha venido a poner de manifiesto la importante labor que realiza el notario como controlador de la legalidad del acto o del negocio jurídico y los importantes efectos positivos que produce dicho control en el sistema económico. Este control de legalidad que realiza el notario tiene, pues, fundamentalmente, dos aspectos: uno activo, procurando adaptar la voluntad de las partes al ordenamiento jurídico, y otro negativo, expulsando de la garantía de la fe pública a aqueIlos que no quieren adecuarse al mismo. La dialéctica entre estos dos principios representa el caballo de batalla del quehacer notarial." Garrido Melero, Martin. "El estatuto del notario en el XXIV Congreso Internacional del Notariado Latino (México, 2004)", en W.AA. El notariado y la reforma de la fe pública, Colegio Notarial de Cataluña - Marcial Pons, Madrid, 2007, p. 75.

${ }^{24}$ "Uno de los principios que informa la actuación notarial es el de calificación, que se manifiesta entre otras expresiones, en la determinación del tipo instrumental y del tipo negocial o del hecho que se ha de cobijar en el documento público. Para poder calificar se exige que el notario sea un profesional del Derecho. Sólo alguien, experto en temas jurídicos, puede determinar el negocio, acto o hecho jurídico que se pretenda instrumentar por los sujetos que requieren de la actuación notarial. Se trata de una operación jurídica que engarza las voluntades de las partes con el fin práctico que ellas persiguen." Pérez Gallardo, Leonardo. "El nomen iuris del acto o negocio jurídico, hecho o circunstancia, contenidos en los documentos públicos notariales", en Anuario Iberoamericano de Derecho Notarial, Segunda Época, No. 2-3, Madrid, 2013-2014, p. 535, constituye uno de los escasos trabajos sobre tan importante materia.
} 
Por último, según el artículo 59 LN, modificado por Decreto Ley 1232, en la conclusión se expresará lo siguiente:

- La fe de haberse leído el instrumento, por el notario o por los comparecientes, a elección de estos

- La ratificación, modificación o indicaciones de los comparecientes, que también serán leídas

- La fe de entrega de bienes que se estipulen en el acto jurídico, si fuese el caso

- La transcripción literal de normas legales cuando en el cuerpo de la escritura se le citen, y se refieran a actos de disposición u otorgamiento de facultades

- La transcripción de cualquier documento o declaración que sea necesario y que pudiera haberse omitido en el cuerpo de la escritura

- La intervención de personas que sustituyen a otras, por mandato, suplencia o exigencia de la ley, siendo que estas anotaciones podrán constar al margen del instrumento.

- Las omisiones que a criterio del notario deban subsanarse para obtener la inscripción de los actos jurídicos objeto del instrumento y que los otorgantes no hayan advertido

- La corrección de algún error u omisión que el notario o los otorgantes adviertan en el instrumento

- La constancia del número de serie de la foja donde se inicia y de la foja donde concluye el instrumento

- La impresión dactilar y suscripción de todos los otorgantes así como la suscripción del notario, con indicación de la fecha en que firma cada uno de los otorgantes, así como cuándo concluye el proceso de firmas del instrumento

- La constancia de haber efectuado las mínimas acciones de control y debida diligencia en materia de prevención del lavado de activos, especialmente vinculado a la minería ilegal u otras formas de crimen organizado, respecto a todas las partes intervinientes en la transacción, específicamente con relación al origen de los fondos, bienes u otros activos involucrados en dicha transacción, así como con los medios de pago utilizados (novedad: Decreto Ley 1232).

El último inciso del artículo 59 LN, introducido por el Decreto Ley 1232, presenta falencias de orden formal y sustantivo. Por lo primero (formal), nótese que el inciso final se ha agregado en forma apresurada, pues la escritura concluye siempre con las firmas de los otorgantes; sin embargo, ahora la constancia de 
control y diligencia podría aparecer teóricamente luego de las firmas, lo que obviamente es incoherente. Es más, véase el inciso $i$, que termina con la letra $y$ que conecta el penúltimo párrafo con el último, pero si bien ello era cierto en la versión original del artículo 59, luego de la modificación del Decreto Ley 1232, el inciso $i$ ya no era el penúltimo párrafo, pero el conector $y$ se mantuvo como fiel testigo de la forma en la que se redactan las normas en nuestro país.

Por lo segundo (sustantivo), parece inaudito que el notariado pretenda ser convertido en sucursal de la "policía", por lo que se le impone la obligación de realizar "acciones de control" para descubrir si los contratantes, o alguno de ellos, se encuentran involucrados en minería ilegal, crimen organizado o lavado de activos con origen ilícito. Es paradójico que la ineficiencia del Estado, que tiene funcionarios, policías, presupuesto, servicio de inteligencia, etcétera, trate de ser compensado mediante el traslado de sus funciones a los notarios, que no cuentan con los medios para el logro de tal finalidad. Con la presente reforma, todo el cuerpo policial y todo el servicio de inteligencia pueden fallar; los notarios, no.

Por otro lado, llama la atención la incongruencia que sufre el propio legislador, cuando el artículo 5 de la Ley 30313 estableció hace pocos meses que el tercero de buena fe se queda con el producto de una falsificación, lo cual normalmente se origina en el crimen organizado y lavado de activos; pero en ese punto el notario no es responsable. Sin embargo, en el Decreto Ley 1232 la solución es distinta, pues el notario debe realizar una indagación para descubrir esas lacras. Un mínimo de coherencia exigiría que el notario también debiera evitar que surjan "terceros de buena fe" nacidos del crimen organizado, pero obviamente en ese ámbito pesó más el interés de entidades financieras, inmobiliarias y constructoras, a quienes no les apetece demasiado la idea de fomentar un tráfico jurídico serio, honesto y ordenado.

La manera más sencilla de dar por cumplidas las "mínimas acciones de control y debida diligencia" que impone la norma, es formular una declaración jurada en que las partes "declaren, bajo responsabilidad, que los fondos, activos y recursos que son materia del presente acto jurídico, han sido obtenidos por mecanismos jurídicos lícitos, previstos por las leyes, por tanto, no se encuentran incursos en actividades de minería ilegal, evasión o defraudación tributaria, crimen organizado en sus diversas modalidades o lavado de activos en general".

Que la declaración del compareciente discrepe con las señales de alarma normalmente aceptadas (traslado de gran cantidad de dinero en efectivo, sucesivas operaciones realizadas muy rápidamente, insolvencia de los contratantes, personas jurídicas sin movimiento, personas jurídicas constituidas en paraísos fiscales, etcétera), no impide que el notario preste el servicio requerido, al cual 
se encuentra legalmente obligado, incluso sujeto a responsabilidad penal (artículo $423 \mathrm{cP}$ ); pero deberá reportar la operación como sospechosa a la autoridad encargada de contrarrestar el lavado de activos.

Por último, la conclusión de la escritura deberá mencionar también el medio formal de pago utilizado para cancelar la obligación, o que no se ha utilizado ninguno, de conformidad con el artículo 5 del texto único ordenado de la Ley 28294, para la Lucha contra la Evasión y para la Formalización de la Economía, aprobado por Decreto Supremo $150-2007-E F,{ }^{25}$ sin perjuicio de las excepciones previstas en el artículo 6. No obstante, el artículo 2 del Decreto Supremo 006-2013-JUS establece la obligatoriedad de realizar pagos a través del sistema financiero cuando el monto sea superior a $\mathbf{S / . \$ 3 , 5 0 0 . 0 0}$ (tres mil quinientos) nuevos soles, pero siempre que "tengan que pagar los usuarios en dichas sedes”, es decir, dentro de las oficinas notariales. Por tanto, el deber legal quedará excluido cuando el pago haya sido efectuado con anterioridad al acto notarial. ${ }^{26}$

\section{Acta de protocolización}

El registro (protocolo) notarial de escrituras públicas no sólo permite extender el instrumento homólogo, sino también las llamadas "actas de protocolización", que son la constancia del notario, que se documenta mediante acta, por la cual se incorpora a su protocolo documentos, normalmente privados, cuando la ley así lo permita. El objetivo de tales actas es proporcionar fecha cierta a los documentos privados, conservarlos con la seguridad que implica el protocolo notarial y tener la posibilidad de contar con traslados o reproducciones.

El acta de protocolización es un instrumento autorizado exclusivamente por el notario, sin otro partícipe. En este caso no se reciben declaraciones de voluntad de los autores de algún acto o negocio jurídico, sino que se limita a dejar constancia escrita, pública y con fe notarial de la incorporación de documentos al final del tomo del protocolo correspondiente.

Según el artículo 65 LN, modificado por Decreto Ley 1232, el acta contendrá lo siguiente:

\footnotetext{
${ }^{25}$ La colaboración de los notarios con la administración pública, "se acentúa en los últimos años, especialmente con la legislación de prevención de blanqueo de capitales". De Mota Salvador, Juan. "Constancia de medios de pago en escrituras", en Gómez-Ferrer Sapiña, Rafael (Coord.), Op. cit., p. 90.

${ }^{26}$ La parte considerativa del Decreto Supremo 006-2013-JUS señala: "el presente Decreto Supremo determina la necesidad de generar mecanismos para conseguir mayor seguridad personal y jurídica a través de la limitación del uso de dinero en efectivo en las transacciones y operaciones contractuales, económicas $u$ otras que se realicen en los oficios notariales, supliéndolas con otras formas o medios de pago".
} 
- Lugar, fecha y nombre del notario

- Materia del documento

- Los nombres de los intervinientes del documento protocolizado, pero con la atingencia de que ellos no comparecieron ante el notario

- El número de fojas de que conste

- Nombre del juez que ordena la protocolización y del secretario, con la mención de la resolución e indicación de encontrarse consentida o ejecutoriada, o la denominación de la entidad que lo solicita

- Tratándose de la protocolización de laudos arbitrales, deberá requerirse la comparecencia del árbitro o uno de ellos designados por el tribunal arbitral para su identificación (novedad: Decreto Ley 1232). Por tanto, en este caso específico, el acta se convierte, en la práctica, en una escritura pública en la cual se produce la declaración ratificatoria de uno de los interesados, que no es otro que el árbitro.

La modificatoria del Decreto Ley 1232 se origina en los casos de fraude inmobiliario llevado a cabo por medio de los laudos arbitrales. Otro tema será evaluar la pertinencia, o no, de la medida adoptada.

Sobre los antecedentes de esta historia, cabe recordar que la flexibilización de la ley de arbitraje, con el fin de "promoverlo", ha dado lugar a que las organizaciones delictivas se aprovechen de tal circunstancia, para lo cual se contó con la indolencia e inacción de los centros arbitrales -en algunos de los cuales hubo infiltrados-, del registro y del propio órgano jurisdiccional, que ha terminado por validar los fraudes. ${ }^{27}$

La modalidad delictiva se inicia con un convenio arbitral falso, que da lugar a un arbitraje amañado en el cual se discute la propiedad o la posesión de un bien inmueble. Ello concluye con el laudo obviamente favorable al falsario, que no tiene dificultades en inscribirse en el registro, gracias, además, a las normas reglamentarias sospechosas que le abrieron las puertas de par en par; por lo cual, de la noche a la mañana, un propietario con título inscrito terminaba despojado. Por supuesto, la trama continúa con la venta inmediata al "tercero de buena fe", que en tal condición exigía la entrega del bien, por lo que el propietario, recién en este momento, se enteraba de que se había convertido en invasor de lo que es suyo.

En este punto hay que reconocer varias causas. La ley de arbitraje, en su afán de ampliar su eficacia, permite que el árbitro ejecute por sí mismo el

\footnotetext{
${ }^{27}$ Véase Gonzáles BarRón, Gunther. "La falsificación: nuevo modo de adquirir la propiedad", en Gaceta Jurídica, Lima, 2015, pp. 195-205.
} 
laudo, lo cual ha constituido una carta blanca para que pida la inscripción, aperciba al registrador y logre inscripciones claramente irregulares. Este un claro ejemplo de una ley privatista al extremo, que, además, ha sido interpretada en forma exagerada. En efecto, si bien es cierto que la norma autoriza la ejecución, ello debe entenderse en el sentido de que el árbitro sólo puede llevar a cabo los actos declarativos de ejecución con eficacia inter partes (por ejemplo: orden de cumplimiento, homologación de la ejecución voluntaria), ${ }^{28}$ pero no los actos de ejecución forzosa, propia o impropia, o que impongan obligaciones o deberes a los terceros, o que requieran el auxilio de la fuerza pública.

El arbitraje presupone el sometimiento voluntario de dos partes a la decisión de un tercero. Entonces, ¿cómo va a ser posible que una institución estatal, como el registro público, se sienta vinculada a ejecutar un laudo entre dos particulares? El arbitraje no pasa de ser un contrato, y un contrato sólo tiene eficacia entre sus partes, pero no frente a los terceros extraños. Por tanto, el laudo no los obliga, y ni siquiera tiene carácter de instrumento público (cuya fecha se opone a terceros).

Así, imperativamente se requiere que el laudo pase por un proceso de ejecución judicial previo a la inscripción, pues se considera un "acto de ejecución impropio". ${ }^{29}$ Por tal motivo, el órgano judicial no puede desentenderse del arbitraje cuando, por mandato de la Constitución, el juez tiene la obligación de velar por la tutela de los derechos y resguardar el debido proceso, el derecho de defensa de la parte ejecutada y la pluralidad de instancias.

En suma, el gran responsable de un arbitraje omnipresente, sin límites, facilitador del fraude inmobiliario, no es otro que el diseño legal-institucional que facilita a ciertos árbitros que decidan cualquier cosa, hasta el robo de lo ajeno en forma impune, así como el propio registro, cuyas normas reglamentarias, sin sustento alguno, han permitido que los laudos puedan inscribirse sin problemas, para el beneplácito de los falsarios.

El Poder Ejecutivo tenía la posibilidad de enfrentar decididamente el tema. Lamentablemente, el Decreto Ley 1232 no presenta soluciones a las múltiples causas. En efecto, la reforma persigue que el notario certifique la identidad del árbitro que emitió la decisión, sin considerar que nunca se han presentado

\footnotetext{
28 "Los árbitros tienen competencia para administrar el proceso de ejecución, pero carecen del poder de ejecución, para lo cual derivaban a la jurisdicción los mandatos de ejecución ya dictados en sede arbitral". LedESMA NARVAEz, MARIANELLA. Jurisdicción y Arbitraje, PUCP, Lima 2009, p. 199.

${ }^{29}$ Tal vez puedan excluirse de esta conclusión los casos en que el propio Estado, como tal, se ha sometido al arbitraje, especialmente en el ámbito de protección de inversiones, por lo que sus órganos se encontrarían obligados al cumplimiento.
} 
problemas en ese punto. Es decir, el remedio no tiene relación alguna con la enfermedad. Por el contrario, la nueva ley debió atacar el secreto con el que actúan los árbitros, la impunidad de la que gozan sin importar el sentido de las decisiones, la dificultad para impugnar el laudo y la posibilidad de afectar a terceros ajenos al arbitraje, sin que nadie haga o diga algo.

Sin duda, el lobby arbitral ha realizado un buen trabajo para lograr que la reforma legal sea edulcorada hasta el grado de que no surta efecto alguno, por lo que el drama de los propietarios, en este ámbito, sigue sin respuesta. ${ }^{30}$

\section{Traslados de los instrumentos protocolares}

Los traslados son copias certificadas de los instrumentos protocolares que el notario ha autorizado en el ejercicio de su función. Si tenemos en cuenta que la escritura pública original queda definitivamente incorporada al protocolo notarial, entonces se hace necesaria su reproducción literal autenticada, a efecto de que los interesados puedan hacer valer sus derechos con un documento que tenga el mismo valor jurídico que el original. Este es uno de los principios del notariado latino: las copias autenticadas tienen idéntico valor probatorio que la escritura, con el fin de invocarlas en sede judicial o extrajudicial.

Los traslados reconocidos por la ley son el testimonio, los partes y la boleta. La práctica de extender "copias simples" no está sustentada en norma alguna, por lo que, en la actualidad, existe la propensión de rechazar tal uso. En todo caso, las copias simples carecen de valor probatorio.

El testimonio contiene la transcripción íntegra del instrumento protocolar, con la fe que da el notario de su identidad con la matriz, la indicación de la fecha y foja donde corre la constancia de encontrarse suscrito por los comparecientes y autorizado por él, rubricado en cada una de sus fojas y expedido con sello, signo y firma, con la mención de la fecha en que se expide (artículo $83 \mathrm{LN}$ ). Este traslado también puede emitirse en formato

\footnotetext{
${ }^{30}$ No cabe reducir el problema, como hacen algunos árbitros en defensa de sí mismos, al hecho de "meter presos a los delincuentes", pues según el análisis costo-beneficio, al cual, curiosamente, algunos de esos defensores son tan adeptos, la persona queda incentivada a cometer delitos cuando el beneficio es extraordinario, y el costo, mínimo, como ocurre en los casos del fraude inmobiliario. Por tanto, la justicia penal no es suficiente para atajar el problema, pues ello no le devuelve a los propietarios sus viviendas robadas. En realidad, lo que se necesita son medidas preventivas para que la propiedad sea realmente inviolable, como dice el artículo 70 constitucional, lo cual exige evitar la inscripción de los despojos, mediante la adecuada publicidad de los procesos arbitrales y los laudos, la imposibilidad de inscribir en agravio de terceros, el control judicial de las ejecuciones, la impertinencia de los laudos para lograr la posesión cuando haya oposición de tercero, asi como la responsabilidad penal cuando el árbitro emita decisión insustentable, según la ley, o invocando hechos falsos. Es curioso que los árbitros pretendan defender su fuero mediante la cláusula constitucional que los considera "jurisdicción", pero sólo aceptan los beneficios, no las cargas (escrutinio público, imparcialidad absoluta y estricta, responsabilidades). Un típico ejemplo de ley del embudo.
} 
digital cuando se cumpla la ley de la materia (artículo 86 LN, modificado por Decreto Ley 1232).

El parte es también una transcripción íntegra del instrumento protocolar, pero con la particularidad de que va dirigido al registro para su inscripción. Aquí también el notario da fe de la identidad con la matriz, la constancia de encontrarse suscrito por los comparecientes y autorizado por él, rubricado en cada una de sus fojas, expedido con su sello y firma, con la mención de la fecha en que se le expide (artículo 85, primer párrafo, LN). Cuando se trata de formato papel, el Decreto Ley 1232 agrega un último párrafo en el artículo 85: "el parte debe constar en papel notarial de seguridad que incorpore características especiales que eviten la falsificación o alteración de su contenido".

Aún se desconoce cómo esto podrá cumplirse, en tanto el único papel con características de infalsificable es el de los billetes que sirven como papel moneda, que se produce en una fábrica especial ubicada en la ciudad de Londres. En tal caso, el alto costo del papel se compensa con la inmensa cantidad de billetes que circulan en la economía; pero eso no sucede con los partes notariales. Por lo demás, parece curioso que se dé más importancia al papel, que sería inmodificable, antes que a la firma del notario, que sería falsificable. En todo caso, la norma ha quedado en suspenso hasta el 1 de abril de 2016, pero su efectividad no parece asegurada, desde que el tipo de papel lo determinan los propios notarios mediante la Junta de Decanos. ${ }^{31}$

Por último, la boleta es un resumen del instrumento protocolar, o la transcripción de las cláusulas o términos que el interesado solicita, con la designación de los otorgantes, naturaleza del acto jurídico, fecha y foja donde corre, y la constancia de encontrarse suscrito por los comparecientes, con la respectiva autorización por el notario, rubricado en cada una de sus fojas, expedida con sello y firma, con la mención de la fecha en que se expide. El notario, cuando lo considere necesario, agregará cualquier referencia que dé sentido o complete la transcripción solicitada (artículo $84 \mathrm{LN}$ ). Este traslado también puede emitirse en formato digital cuando se cumpla la ley de la materia (artículo 86 LN, modificado por Decreto Ley 1232).

La antigua ley del notariado (de 1911) señalaba la obligación de numerar los testimonios que se iban entregando, lo cual exigía que el notario hiciera las atestaciones respectivas en la escritura matriz respecto a cada testimonio

\footnotetext{
3114 DCTF-LN, incorporada por el Decreto Ley 1232: "El papel notarial de seguridad para la expedición del parte, a que se refiere el artículo $85^{\circ}$ de la presente ley, deberá ser de uso uniforme a nivel nacional y de aplicación a partir del 1 de abril de 2016. La Junta de Decanos del Colegios [sic] de Notarios del Perú determinará las características especiales del papel notarial de seguridad y demás acciones necesarias destinadas a su implementación".
} 
expedido. Esta formalidad no se mantiene en la nueva ley, y esta solución debe juzgarse favorablemente, pues la indicación del número de testimonio resultaba superflua y sin ningún fundamento. La antigua obligación se explica en los ordenamientos jurídicos en donde el protocolo es secreto, y los terceros sólo pueden acceder a un traslado cuando tengan un especifico interés para consultarlo; por lo tanto, es necesario llevar un control riguroso respecto a los testimonios expedidos, el nombre del solicitante y el interés justificativo para ello. Sin embargo, tal formalismo resulta superfluo cuando el protocolo es de libre acceso, como en nuestro caso.

Los traslados notariales (testimonio, boleta, parte) pueden expedirse, a elección discrecional del notario, a través de manuscrito, mecanografiado, copia fotostática o por cualquier medio idóneo de reproducción (artículo 86, primer párrafo, LN). Queda en duda si el interesado puede exigir alguno de los mecanismos de reproducción, pero la opinión más aceptable es la afırmativa, pues el traslado es pagado por el usuario, y lo lógico es que él pueda exigir el medio. El Decreto Ley 1232 ha introducido el siguiente párrafo: "Los testimonios, las boletas y los partes expedidos [...] en el caso de remitirse en formato digital, deberán, además, cumplir con las condiciones y requisitos de la ley de la materia". Esto significa que deberán aplicarse las seguridades propias de la normativa de firma digital. Esta fórmula tiene el propósito de validar los traslados digitales presentados en el registro para la inscripción de actos y contratos, con lo cual se evita la remisión informática de los partes y la posterior regularización con papel firmado y sellado, en tanto la versión digital del traslado carecía de base legal.

Es bueno mencionar que el instrumento protocolar consta en soporte papel con firma manuscrita o autógrafa, pero los distintos traslados (copias) pueden extenderse en soporte electrónico, por lo que constituyen documentos electrónicos, ${ }^{32}$ los cuales, en principio, sólo tienen carácter privado y carecen de certeza. Sin embargo, los traslados notariales son instrumentos públicos, por lo que se necesita dotarles de autenticidad. ${ }^{33}$ Así, tratándose del soporte

\footnotetext{
${ }^{32}$ Los documentos electrónicos tienen dos características: "1) están plasmados en un alfabeto técnico y preciso, capaz de describir la realidad, y 2) están representados en una superficie física (magnética o digital). Por consiguiente, ello nos debe llevar a concluir que todos los documentos electrónicos son documentos escritos si bien el lenguaje empleado en dicha escritura no es un lenguaje humano, sino informático (código binario) y los instrumentos gráficos no son la pluma o el bolígrafo sino el teclado o la pantalla del ordenador". Ortega Diaz, Juan Francisco. Contratación, notarios y firma electrónica, Universidad de Los Andes-Temis, Bogotá, 2010, p. 67.

33 "Tradicionalmente, en una cultura juridica apegada al papel, la firma manuscrita ha gozado de una reputación y de un prestigio extraordinarios. La fiabilidad absoluta, que tradicionalmente se liga a la firma manuscrita, no tiene parangón con otros tipos de firma realizados con el concurso de medios técnicos, que persiguen el cumplimiento de los mismos fines pero con mayor grado de seguridad y de fiabilidad. No en vano, la firma manuscrita tradicional presenta riesgos obvios que son minimizados por ese aprecio social". Ibidem, pp. 84-85.
} 


\section{virtual, se necesita la certificación de la firma digital, que requiere de entida- des certificadoras que se basan de claves privadas y claves públicas. ${ }^{34}$ La Ley 27269, modificada por la Ley 27310, y reglamentada por el Decreto Supremo 052-2008-PCM, regula la firma y certificados digitales; ${ }^{35}$ mientras el Decreto Ley 681 establece normas que regulan el uso de tecnologías avan- zadas en materias de documentos e información.}

\footnotetext{
${ }^{34}$ El sistema opera de la siguiente forma: "mediante el uso de las dos claves, el emisor de un mensaje aplicará al mismo su clave privada emitiendo el mensaje cifrado a su destinatario que, al recibirlo, aplicará sobre él la clave pública del emisor, desencriptando el texto y haciéndolo legible. Así, al tornar legible un mensaje aplicando el destinatario la clave pública del emisor, el receptor del mensaje se beneficia de las funciones que cumple la criptografía asimétrica: 1. El emisor queda perfectamente identificado (identificación). 2. Obtiene la seguridad de que el mensaje fue emitido y firmado por el poseedor de la clave privada que corresponde a la clave pública (autenticación). 3. Obtiene seguridad de que el mensaje no ha sido alterado, pues de haberlo sido, el mensaje hubiera resultado ilegible (integridad). 4. Desaparece la posibilidad de que el emisor niegue la autoria de la firma, pues si es posible desencriptar el mensaje mediante la clave pública, es evidente, muy fácilmente demostrable, que el mensaje fue firmado mediante la clave privada que únicamente posee el emisor (no repudio). 5. Tanto el emisor como el receptor obtienen un altísimo grado de confidencialidad, sin necesidad de intercambiar claves con anterioridad. Esto es especialmente importante en canales de comunicación inseguros, como internet, $y_{1}$ en general, en todas las redes telemáticas abiertas (confidencialidad). Al firmar un documento electrónico mediante criptosistema asimétrico, tanto el emisor como el receptor tendrán la seguridad de que sólo ellos podrán conocer el contenido del mensaje". Ibidem, pp. 99-100.

${ }^{35}$ Artículo 1, Ley 27269: "La presente Ley tiene por objeto regular la utilización de la firma electrónica otorgándole la misma validez y eficacia jurídica que el uso de una firma manuscrita u otra análoga que conlleve manifestación de voluntad. Entiéndase por firma electrónica a cualquier símbolo basado en medios electrónicos utilizado o adoptado por una parte con la intención precisa de vincularse o autenticar un documento cumpliendo todas o algunas de las funciones caracteristicas de una finca manuscrita".

Artículo 2, Ley 27269: "La presente ley se aplica a aquellas firmas electrónicas que, puestas sobre un mensaje de datos o añadidas o asociadas lógicamente a los mismos, pueden vincular e identificar al firmante, así como garantizar la autenticación e integridad de los documentos electrónicos".

Artículo 3, Ley 27269: "La firma digital es aquella firma electrónica que utiliza una técnica de criptografia asimétrica, basada en el uso de un par de claves único; asociadas una clave privada y una clave pública relacionadas matemáticamente entre sí, de tal forma que las personas que conocen la clave pública no puedan derivar de ella la clave privada".

Artículo 4, Decreto Supremo 052-2008-PCM: "Los documentos electrónicos firmados digitalmente dentro del marco de la Infraestructura Oficial de Firma Electrónica deberán ser admitidos como prueba en los procesos judiciales y/o procedimientos administrativos, siempre y cuando la firma digital haya sido realizada utilizando un certificado emitido por una Entidad de Certificación acreditada en cooperación con una Entidad de Registro o Verificación acreditada, salvo que se tratara de la misma entidad con ambas calidades y con la correspondiente acreditación para brindar ambos servicios, asimismo deberá haberse aplicado un software de firmas digitales acreditado ante la Autoridad Administrativa Competente. Esto incluye la posibilidad de que a voluntad de las partes pueda haberse utilizado un servicio de intermediación digital.

La firma digital generada en el marco de la Infraestructura Oficial de Firma Electrónica garantiza el no repudio del documento electrónico original. Esta garantía no se extiende a los documentos individuales que conforman un documento compuesto, a menos que cada documento individual sea firmado digitalmente.

La comprobación de la validez de un documento firmado digitalmente se realiza en un ambiente electrónico aplicando el software de verificación de la firma digital. En caso de controversias sobre la validez de la firma digital, el juez podrá solicitar a la autoridad administrativa competente el nombramiento de un perito especializado en firmas digitales, sin perjuicio de lo dispuesto por los artículos $252^{\circ}, 264^{\circ}$ y $268^{\circ}$ del Código Procesal Civil.

$\mathrm{Si}$ el documento firmado digitalmente se ha convertido en una microforma o microarchivo, el notario o fedatario con diploma de idoneidad técnica vigente cumplirá con las normas del Decreto Legislativo № 681 y cuidará de cumplir aquellas normas pertinentes de la ley y de este reglamento".
} 
Por último, si el instrumento protocolar no está suscrito por todos los comparecientes, el notario tiene prohibido expedir traslados. Es obvio que mientras no se completen todas las firmas del instrumento, este se encuentra incompleto; como tal, carece de eficacia jurídica. En tal caso, el notario podrá expedir una certificación especial en la cual se deje constancia de que el instrumento ha sido extendido, pero que no ha sido suscrito (artículo $90 \mathrm{LN}$ ).

\section{Conclusiones}

El Decreto Ley 1232 tiene problemas formales, pues la ley de delegación del Congreso al Poder Ejecutivo no contemplaba las facultades de modificación de la ley del notariado. Sin embargo, haciendo la salvedad de esta cuestión, que deberá resolver el propio Congreso, el hecho concreto es que la reforma normativa emprendida es positiva, en tanto la escritura pública queda fortalecida con los deberes impuestos al notario, especialmente en orden a la identificación de las personas, con la consiguiente responsabilidad por la inobservancia. Es de esperar, por tanto, que los órganos de control del notariado asuman sus obligaciones con rigurosidad. No obstante, el Decreto Ley 1232 se equivoca en cuanto olvida enfrentar los fraudes producidos desde el registro $\mathrm{y}$ desde el arbitraje, por lo que aún subsisten vastos sectores de inseguridad en el tráfico jurídico. 